\title{
POTENTIAL IMPROVEMENT FOR FOREST COVER AND FOREST DEGRADATION MAPPING WITH THE FORTHCOMING SENTINEL-2 PROGRAM
}

\author{
L. Hojas-Gascón a, d, A. Belward ${ }^{\text {a }}$, H. Eva ${ }^{\mathrm{a}^{*}}$, G. Ceccherini $^{\mathrm{a}}$, O. Hagolle ${ }^{\mathrm{b}}$, J. Garcia $^{\mathrm{c}}$, , P. Cerutti $^{\mathrm{d}}$ \\ ${ }^{a}$ European Commission Joint Research Centre, Via E. Fermi 2749, 21027 Ispra (VA), Italy - hugh.eva@jrc.ec.europa.eu \\ ${ }^{\mathrm{b}}$ CESBIO / CNES, Toulouse, France - olivier.hagolle@cnes.fr \\ ${ }^{\mathrm{c}}$ Unidad de Investigación de Teledetección, Dr. Moliner 50, 46100 Valencia, Spain - j.garcia.haro@uv.es \\ ${ }^{\mathrm{d}}$ CIFOR Center for International Forestry Research, Bogor Barat 16115, Indonesia - p.cerutti@ cgiar.org
}

KEY WORDS: Forest cover, Forest degradation, SPOT, Sentinel-2, REDD+, Tropical Dry forest.

\begin{abstract}
:
The forthcoming European Space Agency's Sentinel-2 mission promises to provide high $(10 \mathrm{~m})$ resolution optical data at higher temporal frequencies (5 day revisit with two operational satellites) than previously available. CNES, the French national space agency, launched a program in 2013, 'SPOT4 take 5', to simulate such a dataflow using the SPOT HRV sensor, which has similar spectral characteristics to the Sentinel sensor, but lower $(20 \mathrm{~m})$ spatial resolution. Such data flow enables the analysis of the satellite images using temporal analysis, an approach previously restricted to lower spatial resolution sensors. We acquired 23 such images over Tanzania for the period from February to June 2013. The data were analysed with aim of discriminating between different forest cover percentages for landscape units of 0.5 ha over a site characterised by deciduous intact and degraded forests. The SPOT data were processed by one extracting temporal vegetation indices. We assessed the impact of the high acquisition rate with respect to the current rate of one image every 16 days. Validation data, giving the percentage of forest canopy cover in each land unit were provided by very high resolution satellite data. Results show that using the full temporal series it is possible to discriminate between forest units with differences of more than $40 \%$ tree cover or more. Classification errors fell exclusively into the adjacent forest canopy cover class of $20 \%$ or less. The analyses show that forestation mapping and degradation monitoring will be substantially improved with the Sentinel-2 program.
\end{abstract}

\section{INTRODUCTION}

\subsection{Monitoring deforestation and forest degradation}

For more than a decade the monitoring of deforestation has successfully been carried out at regional levels using moderate spatial resolution satellite data, predominantly from the Landsat sensor (Achard et al. 2009, INPE 2014, FAO, JRC, SDSU and UCL 2009), which has $30 \mathrm{~m}$ spatial resolution and a revisit frequency of 16 days. More recently the University of Maryland, in conjunction with Google, have produced global forest change maps (the Global Forest Maps) based on a synthesis of the Landsat archive for the years 2000-2012 (Hansen et al. 2013).

The activities proposed in 2011 under the Reduced Emissions from Deforestation and forest Degradation (REDD+) framework, brought new requirements for monitoring deforestation and forest degradation at national levels and finer scales (UNFCCC 2011). Deforestation was defined as a direct human-induced decrease in tree crown cover below 10-30\% of forest areas with a minimum size of 0.05-1 ha (UNFCCC 2001), and degradation as a loss of carbon stock in forest areas with a decrease in the tree crown cover not below the 10-30\% threshold (IPCC 2003).

Participatory countries should implement forest monitoring systems that use an appropriate combination of remote sensing and ground-based forest carbon inventory approaches, with a focus on estimating anthropogenic forest area changes and forest carbon stocks (UNFCCC 2009, p.12). Preliminary comparisons of the Global Forest Maps with very high resolution satellite data has already highlight that the spatial resolution of the Landsat sensor is too coarse for monitoring deforestation with high accuracy in the context of REDD+, and therefore higher (c. $5-10 \mathrm{~m})$ spatial resolution satellite data should be employed (CIFOR 2015).

The addition of forest degradation in the program implies that the estimations of forest carbon stock changes need to be based, not only on monitoring transitions of land cover classes (e.g. forest to non-forest), but also on transitions within the forest class when there is a loss of carbon sequestration (e.g. forest with more than $30 \%$ crown cover into forest with less than $10 \%$ crown cover). In this study carried out over a test site in Tanzania, we have considered forest as an area of land with at least 0.5 ha and a minimum tree crown cover of $10 \%$, with trees which have, or have the potential, to reach a minimum height of 5 meters at maturity in situ, according to the definition adopted by the Tanzanian national REDD+ strategy (UN-REDD 2013).

\subsection{The Sentinel-2 program}

The European Union's first Earth Observation programme, Copernicus, is building a series of technologically advanced satellites (the Sentinels), which includes the Sentinel-2 satellites. Sentinel-2 aim to contribute providing inputs for services relying on multi-spectral high-resolution optical observations over global land surfaces, like SPOT and Landsat satellites, but also attempt to cover current limitations with the addition of the technical needs for new requirements. These include higher revisit frequencies, more spectral bands with narrower bandwidths and finer spatial resolutions, in order to improve services as vegetation monitoring (ESA, 2010).

\footnotetext{
Corresponding author.
} 
The design of the Sentinel-2 platform benefited from the experience and lessons learned from other satellites building on their technology. The selection of the spectral bands has been guided by the Landsat, SPOT-5, MERIS and MODIS heritage (ESA, 2010). The Multi Spectral Instrument (MSI)'s 13 spectral bands' centre range from 0.433 to $2.19 \mu \mathrm{m}$. There are four visible and near-infrared bands at $10 \mathrm{~m}$ spatial resolution, three red edge, one near-infrared and two SWIR at $20 \mathrm{~m}$, and three channels to help in atmospheric correction and cloud screening at $60 \mathrm{~m}$ (Drusch et al., 2012). When complete, the Sentinel-2 program will have two satellites offset in orbit operating simultaneously on opposite sides (Sentinel-2A and Sentinel2B), each carrying the same instruments. Sentinel-2A is scheduled for launch in June 2015 and Sentinel-2B in late 2016. Together these two satellites will provide coverage every five days at the equator with a $290 \mathrm{~km}$ field of view (ESA, 2010).

Forest monitoring is one of the priority services of the Global Monitoring for Environment and Security (GMES) programme for which Sentinel-2 has been tailored. In fact, the revisit requirements were driven by vegetation monitoring, for which those of Landsat and SPOT were not enough. Sentinel-2 observations are explicitly intended to develop key inputs required for Kyoto protocol reporting. Potentially, they could contribute to the Baseline Mapping Service for the REDD+ programme (ESA, 2010). The Copernicus plans also aim for multiple global acquisitions and a free and open access data policy (European Commission, 2013), similarly to Landsat.

\subsection{Time series for forest cover mapping}

Short revisit periods are potentially important to monitor forest at national/regional scales. Firstly, the increased coverage provides more opportunity for acquiring cloud-free images, particularly important in tropical regions (Beuchle et al., 2011). Secondly, because they should allow us to exploit seasonal differences in canopy reflectance characteristics as a means of discriminating between forest cover types and different forest conditions (e.g. closed and open forests, or deciduous and degraded forests), which is especially important for the dry forest.

With the advent of the Sentinel-2, data availability over target areas will increase, allowing temporal analysis previously restricted to moderate $(>100 \mathrm{~m})$ spatial resolution satellite data (such as MODIS), to be employed in the monitoring of forests at finer spatial resolutions. Sentinel-2 will bring an improvement in the spatial resolution (with the three visible and a near infrared bands at $10 \mathrm{~m}$ ), which will allow a more accurate assessment of deforestation and forest degradation areas taking the minimum scales defined by the UNFCC, and in the spectral sampling (i.e. higher amount of bands with narrower width), with the inclusion of three bands in the red edge, which has shown to be useful for quantitative assessment of vegetation status (Frampton et al., 2013).

\section{$1.4 \quad$ SPOT4 Take 5}

Whilst the Sentinel have not been launched yet, in order to prepare for the use of its data, on the $29^{\text {th }}$ of January 2013 the French space agency CNES lowered the orbit of SPOT4 to put it on the same repeat cycle of Sentinel-2 until $19^{\text {th }}$ June of the same year. During this period, SPOT passed over by the same 45 selected places every 5 days, one of them in the dry forest in Tanzania as requested by JRC. SPOT4 records in 5 spectral bands: three visible, one near-infrared and one SWIR at $20 \mathrm{~m}$ spatial resolution (Hagolle et al., n.d.). This experiment, SPOT4 Take 5, does not simulate the full spectral and radiometric capabilities of Sentinel-2, but does simulate the revisit frequency and the spatial resolution of Sentinel-2.

For the selected place in Tanzania we obtained 23 SPOT images from $6^{\text {th }}$ Feb to $19^{\text {th }}$ June 2013 at level $2 \mathrm{~A}$ (ortho-rectified surface reflectance data provided with a cloud mask). They cover an area of 360.000 ha and a period ranging from the end of the wet season to deep into the dry season.

This paper examines whether improved temporal sampling at high spatial resolution $(20 \mathrm{~m})$ with satellite data actually improves our knowledge of deforestation and forest degradation in dry forest ecosystems, such as those found in Tanzania. For this we will: 1) estimate the increment of data availability, by comparing the cloud free image area of SPOT4 Take 5 with that of Landsat for the same period; 2) evaluate the improvement of the temporal resolution, by comparing the time series of SPOT4 Take 5 with that from MODIS; and 3) estimate the improvement of forest classification accuracy, by calculating the separability of forest classes, with Sentinel-2 A and B and only with (the most proximate) Sentinel-2 A.

\section{METHODOLOGY}

\subsection{Study area and reference data}

The study area is located in the Somalia-Masai ecoregion, in the dry highlands of Central Tanzania. The climate is semiarid; the rainfall is less than $500 \mathrm{~mm}$ per year with high interannual variation, the mean monthly temperature between 20 and $25^{\circ} \mathrm{C}$, and it has a well-defined arid season from beginning of May to end of November. Most of the region is covered with deciduous bushland and thicket (Acacia-Commiphora is the climax vegetation), which grade into evergreen and semi-evergreen bushland and thicket on the lower slopes of the mountains. At higher altitude in the mountains dry forests dominate.

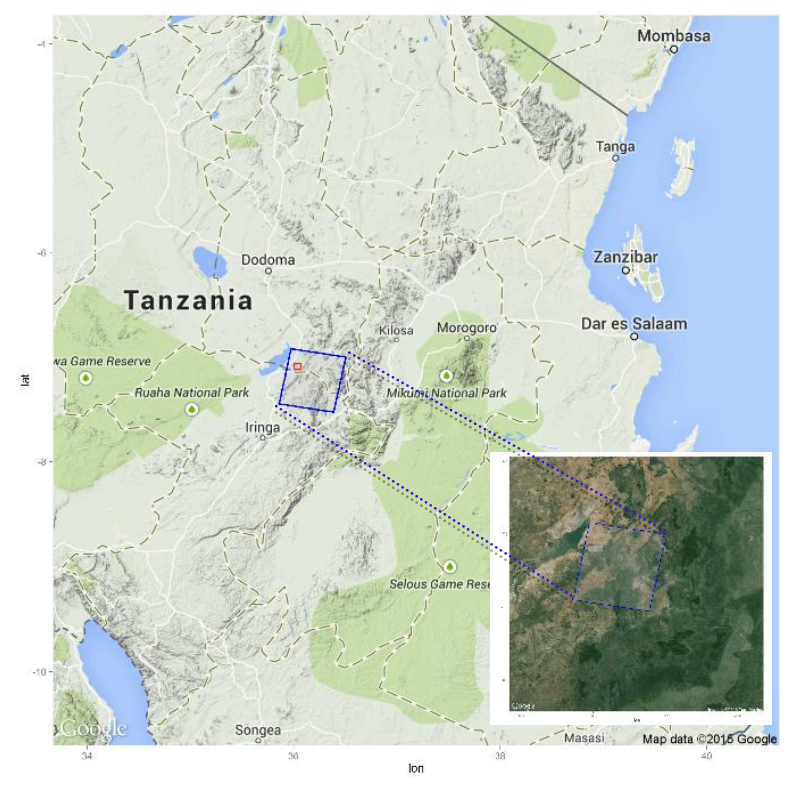

Figure 1. Study area 
The area covered by the SPOT images (blue polygon, Figure 1) is centred at Lat Long (-7.226 36.182), between the Dodoma and the Iringa regions. To the north there are agriculture fields and to the South a mosaic of degraded forest, which was fully covered by forest in 1980. From the Landsat archive we can see that severe deforestation and degradation took place between 1983 and 1994, and in less degree between 1994 and 2011.

A $0.5 \mathrm{~m}$ spatial resolution pan-sharpened multispectral image acquired by the WorldView-2 satellite on the $4^{\text {th }}$ September 2010 was used as reference data, along with field data collected in 2012 (Hojas Gascón and Eva, 2014). It covers an area of 5.000 ha centred at Lat Long $(-7.092,36.035)$ (red polygon, Figure 1).

\subsection{Data availability}

From the cloud occurrence maps provided with the data we summed up the cloud free data frequency for each pixel in the SPOT scene area simulating 10 day (Sentinel-2A) and 5 day (Sentinel-2A and 2B) frequency acquisition.

We also acquired the available Landsat- 8 images for the same period comprised by the SPOT4 Take 5 data and produced the cloud free data frequency map for comparison.

\subsection{SPOT image segmentation}

To divide the images in land units we created two 'seasonal' mosaics, using SPOT images from the wet and dry season respectively. These were then segmented in combination to create polygons of a minimum mapping unit (MMU) of 0.5 ha and 1 ha size. This method was employed so as to retain and discriminate land features that may be distinct in either season.

NDVI, SAVI and MSAVI indices were calculated for the polygons. Analysis showed no significant difference between NDVI and SAVI trends, and the he MSAVI was not found to be effective at discriminating between woody and non-woody vegetation. For easy of processing we reduced the data to the NDVI series.

The NDVI was calculated for each single data image and for the layer stack. From the layer stack we extracted the average NDVI for each of the segments created from the seasonal mosaic. In the segmentation at a MMU of $1 \mathrm{ha}$, the average polygon size was 5.5 ha and the maximum 25 ha. In the segmentation at a MMU of 0.5 ha the average was 1 ha and the maximum 5 ha.

\subsection{Object vegetation classification}

The SPOT data was classified in a two steps processing.

Firstly, the WorldView-2 image was segmented so as to obtain polygons with a mean of 0.1 ha. Areas of bare soil and grass were identified using a 5\% reflectance threshold in the red channel. Woody vegetation was then divided into tree cover (woody vegetation higher than $5 \mathrm{~m}$ ) and shrub cover (woody vegetation lower than $5 \mathrm{~m}$ ). Field data provided information on the ratio of woody vegetation height to crown width, which was found to be around 1 . This was effected by classifying crown width less than $5 \mathrm{~m}$ as shrub formations.

Secondly, the segments from the SPOT data containing the NDVI profiles were then cross tabulated with the very high resolution (VHR) reference data. Therefore the segments from the SPOT data contain proportion of tree cover, shrub cover and non-woody land cover (grass or bare soil). As the data come from different dates, fine spatial resolution RapidEye data of 2013 were screened, so as to remove any areas that had undergone major land cover changes between the acquisition of the Worldview-2 data and the SPOT data. We then classified each segment by its proportions of the three elements with 6 category levels $(0-10,10-20,20-40,40-60,60-80$ and 80-100 cover percentages). For easy of nomenclature we combine the woody and tree proportions in a simple concatenation, for example, class $\mathrm{W} 100 \mathrm{~F} 00$ is all woody vegetation, of which trees (forest) is the only component, class W40F20 has $40 \%$ of woody vegetation, of which $20 \%$ is trees and $20 \%$ shrubs, hence $60 \%$ non-woody vegetation.

\subsection{Extraction of NDVI profiles}

The NDVI profiles were examined by vegetation classes. Cloud-affected dates were removed from the series by averaging proximate date values.

Figure 2 shows that generally the NDVI of the land units falls from a peak at the start of the observation period (end of the wet season) until the end of the period (deep into the dry season). We also noted that the mean NDVI from the different classes pass from being very divergent at the end of the wet season to be very similar in the dry season.

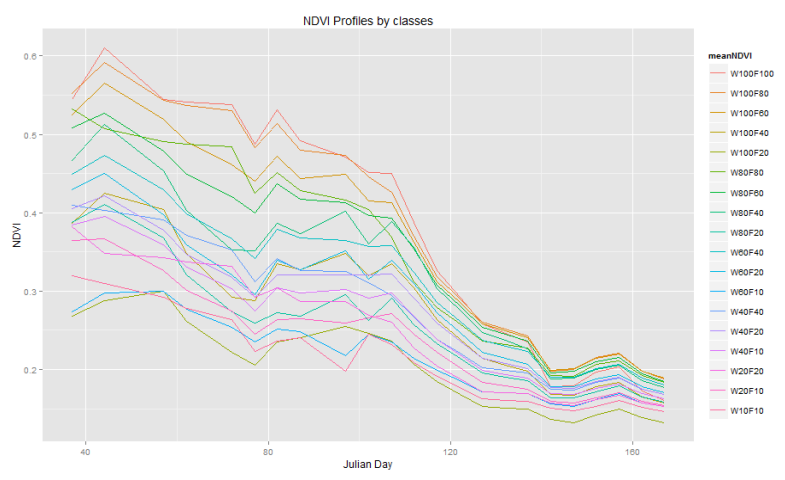

Figure 2. NDVI profiles from by vegetation classes.

\subsection{Class separability}

\subsubsection{Jeffries-Matusita Distance}

The Jeffries-Matusita distance (hereafter JM distance) is a statistical measure of distance between two distributions (Swain, 1972). The JM distance is defined as:

$$
\mu=\sqrt{2\left(1-\mathrm{e}^{-6}\right)}
$$

$$
\alpha=\frac{1}{a}\left(\mu_{a}-\mu_{b}\right)^{T}\left(\frac{C_{a}-C_{b}}{2}\right)^{T}\left(\mu_{a}-\mu_{b}\right)+\frac{1}{2} \ln \left(\frac{\frac{2}{2}\left|C_{a}+C_{b}\right|}{\sqrt{|| C_{a}|x| C_{b} \mid}}\right)
$$

where $\quad \mathrm{a}$ and $\mathrm{b}$ are the two distributions

$\mathrm{C}$ is the covariance matrix

$\mu$ is the mean vector

$\mathrm{T}$ is the transposition function

The JM distance is asymptotic to $\sqrt{2}$ and as such, a value of $\sqrt{2}$ suggests that the two distributions are very separable. The JM distance is widely used in remote sensing applications (Ghiyamat et al., 2013; Padma and Sanjeevi, 2014) to determine 
how distinct, and thus separable, different land cover classes or spectral signals are from each other.

Our goal is to assess the potential of the SPOT time series (simulating Sentinel-2) to discriminate between different forest classes. We calculated the JM taking full advantage of the Sentinel-2 repetitive observations (i.e. 5 days), and also simulating the revisit frequency with just one Sentinel (i.e. 10 days) and the current status (i.e. 16 days), by excluding half and two third of NDVI measurements, respectively.

\subsubsection{Random Forest}

Random Forest is a learning algorithm widely used in the statistical community to cluster data in different classes (among other analysis), constructing a multitude of decision trees at training time (Breiman, 2001). It has been shown to be effective at land cover classification (Rodriguez-Galiano et al., 2012). Our data were examined in Random Forest with a training of 150 of the 832 sample sites, also simulating 5 days, 10 days and 16 days revisit frequency.

\section{RESULTS AND CONCLUSIONS}

\subsection{Cloud free image area}

For the full SPOT scene $90 \%$ of the area is acquired cloud free at least once during the five month period of the Spot 4 Take 5 experiment simulating one Sentinel-2 (an image every 10 days). This rises to $99 \%$ with Sentinel-2 A and B (acquiring images every 5 days). Figure 3 shows the increment of cloud free data frequency with both Sentinel-2 (SPOT) with respect to Landsat8 during the same period. Combining both satellites (image not shown) the scene coverage is of $100 \%$.
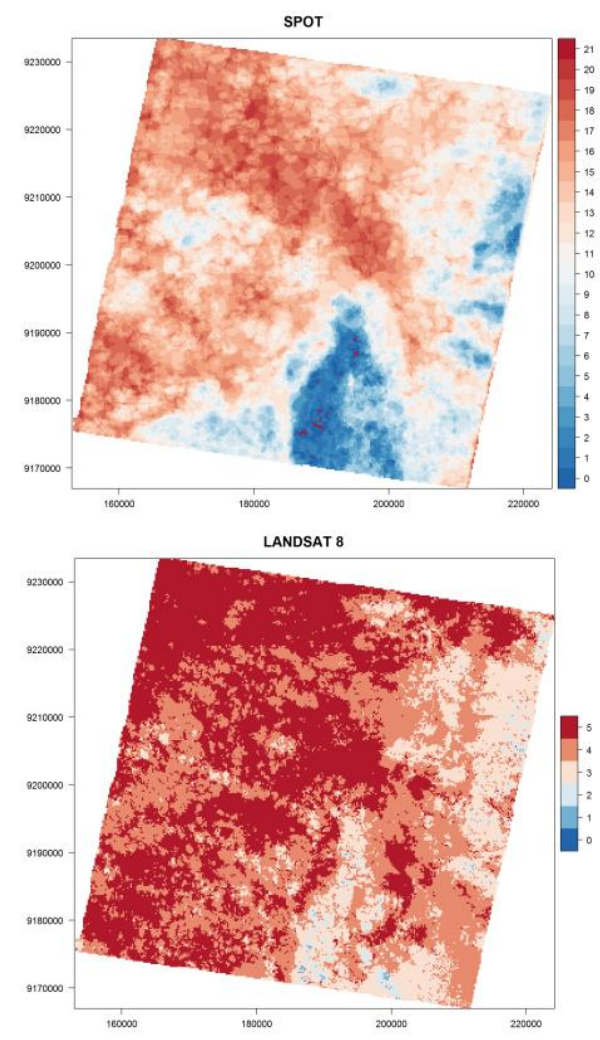

Figure 3. Cloud free data frequency maps with SPOT (top) and Landsat-8 (bottom).

\subsection{NDVI time series}

The averaged SPOT NDVI time series was compared to that obtained with the $250 \mathrm{~m}$ spatial resolution MODIS sensor (Figure 4). The latter has been produced from mean NDVI records from 2000 to 2012 in 16-days periods across the study area. Taking into account that the SPOT time series is a one single acquisition composite, we can say that it corresponds well with the smoothed MODIS product, except in the transitional period between the wet and the dry season. The dip in the profile at this period could be caused by an anomaly in temperature or rainfall regime or to the low quality of the cloud flagging.

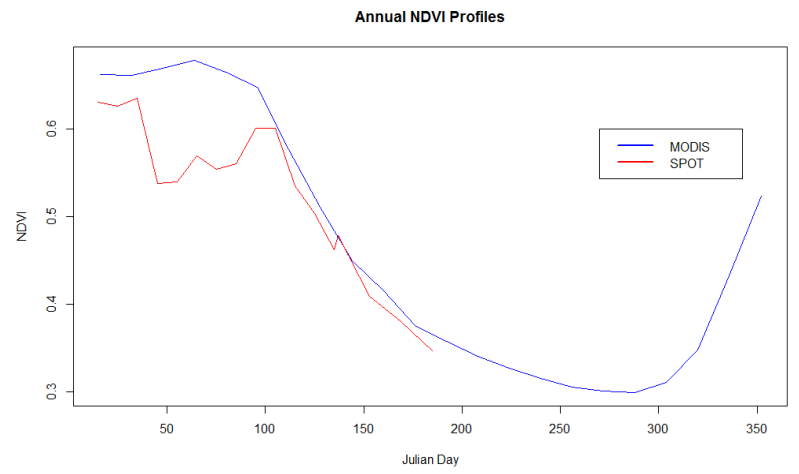

Figure 4. NDVI profile from SPOT and MODIS.

\subsection{Forest classification}

\subsubsection{Jeffries-Matusita Distance}

Sentinel A+B: We present in the appendix the matrix of the JM distance between the different forest classes (Figure 4). For the sake of simplicity, JM distance ranges from 0 to 1414 . The bigger the distance, the better the separability. We can see that JM distance within classes which exhibite small differences in forest cover (i.e. 20\%) is small. Conversely, when the forest cover falls from $40 \%$ on, the distance increases, thus rending easier the discrimination between the corresponding classes. For example, this is true in the case of $\mathrm{W} 100 \mathrm{~F} 80$ where JM distance from W100F60 is only 78, whereas the distance from W100F40 is 339 .

Sentinel A: We have computed the matrix of the JM distance between the different forest classes also in the case of Sentinel A (not shown here). For this configuration we used half of the observations, in order to simulate the 10 day revisit time. To wrap up, if we compute the mean of the ratio between the JM distance with all the observations (i.e. Sentinel $A+B$ ) and half of the observations, we obtain a positive increment of $5.7 \%$ in the distance when using both satellites. This means that, overall, there is an improvement of separation capabilities by increasing the frequency of observations. However, this small value of the increment might be due to the fact that many forest classes are undistinguishable (see Figure 2), and reducing or increasing the frequency does not always help to differentiate them. Also note that the relatively high values of the standard deviation of NDVI (not shown in the graphic) do not always allow the complete separability within two similar classes, resulting often in a partial overlap. 
Current acquisition: The same procedure has been applied also for the case of the current frequency acquisition of satellite data of similar spatial resolution (i.e. 16 days), and so only one third of the observations were retained. In this case, the mean of the ratio of the corresponding JM distances indicates an improvement up to $14.5 \%$ when using Sentinel A and B, with respect to the current acquisition frequency. Again, there is always the issue of the separability between close classes that might lower this statistic.

\subsubsection{Random Forest}

\section{Sentinel A+B:}

\begin{tabular}{|l|l|l|l|l|l|l|l|}
\hline \multicolumn{2}{|c|}{} & \multicolumn{2}{|l}{ SPOT } \\
\cline { 2 - 8 } \multicolumn{2}{|c|}{} & F100 & F80 & F60 & F40 & F20 & F10 \\
\hline \multirow{6}{*}{ WV2 } & F100 & 242 & 151 & 40 & 10 & 6 & 5 \\
\cline { 2 - 8 } & F80 & 77 & 567 & 176 & 25 & 3 & 16 \\
\cline { 2 - 8 } & F60 & 16 & 209 & 442 & 147 & 19 & 44 \\
\cline { 2 - 8 } & F40 & 4 & 17 & 158 & 342 & 119 & 72 \\
\cline { 2 - 8 } & F20 & 2 & 0 & 18 & 138 & 232 & 190 \\
\cline { 2 - 8 } & F10 & 2 & 1 & 7 & 7 & 121 & 670 \\
\hline
\end{tabular}

Table 1. Confusion matrix of forest classification with SPOT simulating Sentinel-2 A and B in comparison to Worldview-2.

From the confusion matrix (Table1) we can assess the class separability and hence assess by what percentage forest cover would have to fall to be correctly identified. We note that a change of two classes (i.e. $40 \%$ fall in forest cover) is required to ensure correct identification (e.g. from F100 to F60), with a probability of $95 \%$ approximately. The detection of $20 \%$ forest cover loss has a risk of misclassification by $20 \%$ approximately.

\section{Sentinel A:}

\begin{tabular}{|l|l|l|l|l|l|l|l|}
\hline \multicolumn{2}{|c|}{} & \multicolumn{2}{|l}{ SPOT } \\
\cline { 2 - 8 } \multicolumn{2}{|c|}{} & F100 & F80 & F60 & F40 & F20 & F10 \\
\hline \multirow{6}{*}{ WV2 } & F100 & 240 & 151 & 41 & 10 & 7 & 5 \\
\cline { 2 - 8 } & F80 & 78 & 556 & 183 & 27 & 5 & 15 \\
\cline { 2 - 8 } & F60 & 15 & 217 & 442 & 144 & 21 & 38 \\
\cline { 2 - 8 } & F40 & 5 & 19 & 158 & 337 & 116 & 77 \\
\cline { 2 - 8 } & F20 & 2 & 1 & 18 & 141 & 233 & 185 \\
\cline { 2 - 8 } & F10 & 1 & 1 & 8 & 8 & 129 & 664 \\
\hline
\end{tabular}

Table 2. Confusion matrix of classification with SPOT simulating Sentinel-2A in comparison to Worldview-2.

The confusion matrix from the SPOT data with a 10 days acquisition frequency does not give very different results to the previous one. Random Forest analysis upholds our previous findings using the Jeffries-Matusita Distance: close classes (cover difference smaller than 20\%), are difficult to discriminate; conversely, when the forest cover difference between two classes is greater or equal to $40 \%$, the separability is easy.

\section{Current acquisition:}

\begin{tabular}{|l|l|l|l|l|l|l|l|}
\hline \multicolumn{2}{|c|}{} & \multicolumn{2}{|l}{ SPOT } \\
\cline { 3 - 8 } \multicolumn{2}{|c|}{} & F100 & F80 & F60 & F40 & F20 & F10 \\
\hline \multirow{6}{*}{ WV2 } & F100 & 225 & 151 & 39 & 23 & 12 & 4 \\
\cline { 2 - 8 } & F80 & 81 & 513 & 214 & 40 & 3 & 13 \\
\cline { 2 - 8 } & F60 & 10 & 229 & 405 & 150 & 34 & 49 \\
\cline { 2 - 8 } & F40 & 3 & 24 & 170 & 293 & 114 & 108 \\
\cline { 2 - 8 } & F20 & 2 & 1 & 26 & 130 & 207 & 214 \\
\cline { 2 - 8 } & F10 & 2 & 2 & 16 & 16 & 156 & 631 \\
\hline
\end{tabular}

Table 3. Confusion matrix of classification with the current acquisition in comparison to Worldview-2.

In the case of the current acquisition frequency, Random Forest results give smaller improvement respect to the higher frequencies than the JM distance. The detection of $20 \%$ forest cover loss has a risk of misclassification of $25 \%$ approximately, while the detection of $40 \%$ forest cover loss of only a bit more than $5 \%$.

Both JM distance and Random Forest analysis were done at a 0.5 and 1 ha MMU. However little differences were found between them and so only the tables with the 0.5 ha are presented.

\subsection{Conclusions}

The increased provision of medium $(\sim 10 \mathrm{~m})$ spatial resolution data acquisition from its current (c.16 days) to 10 days with one Sentinel platform, and 5 days with two operating platforms, promises to bring higher potential for detecting and quantifying forest degradation. Using the $20 \mathrm{~m}$ resolution SPOT4 Take 5 data, processed to a simple vegetation index (NDVI) we have shown that forest degradation can be detected when a reduction of $40 \%$ canopy cover or more occurs in 0.5 ha land units. This is valid for both 5 and 10 day acquisitions. Lower reductions in canopy cover are also detectable, however, with a higher $(\sim 20$ $5 \%$ ) chance of misclassification.

Deforestation and forest degradation monitoring in the context of REDD+ require change detections of $10 \%$ and less than $10 \%$ respectively in the forest cover of land units of 0.05-1 ha. Here we could only discriminate classes with forest cover with more than $40 \%$ difference. However, the results should underestimate the potential of Sentinel, which has a finer $(10 \mathrm{~m})$ spatial resolution and finer band widths. At the same time data were available only for a limited period (5 months) of the year.

The development of better indices and the employment of wave analysis (e.g. Fourier) to characterize the vegetation changes over the full growing season, and eventually to historical data, should provide more robust results. Further improvement could be made by the integration of Landsat - and even MODIS data. 


\section{ACKNOWLEDGEMENTS}

This work was partly funded under a grant from CIFOR, the Center for International Forestry Research.

The authors would like to thank Cesbio for providing of the Spot4 Take 5 dataset needed to perform this research.

\section{REFERENCES}

Achard F., Beuchle R., Bodart C. et al. 2009. Monitoring forest cover at global scale: the JRC approach. Proceeedings of the 33rd International Symposium on Remote Sensing of Environment (ISRSE), 4-8 May 2009, Stresa,Italy, p. 1-4.

Breiman, L., 2001. Random forests. Mach. Learn. 45, 5-32.

Beuchle, R., Eva, H.D., Stibig, H.-J., Bodart, C., Brink, A., Mayaux, P., Johansson, D., Achard, F., Belward, A., 2011. A satellite data set for tropical forest area change assessment. Int. J. Remote Sens. 32.

Drusch, M., Del Bello, U., Carlier, S., Colin, O., Fernandez, V., Gascon, F., Hoersch, B., Isola, C., Laberinti, P., Martimort, P., Meygret, A., Spoto, F., Sy, O., Marchese, F., Bargellini, P., 2012. Sentinel-2: ESA's Optical High-Resolution Mission for GMES Operational Services. Remote Sens. Environ. 120, 2536.

ESA, 2010. GMES Sentinel-2 Mission Requirements Document.

European Commission, 2013. Commission Delegated Regulations (EU) No 1159/2013 of 12 July 2013. Off. J. Eur. Union.

FAO, JRC, SDSU and UCL 2009. The 2010 Global Forest Resources Assessment Remote Sensing Survey: an outline of the objectives, data, methods and approach. Forest Resources Assessment Working Paper 155. FAO,Rome, Italy.

Frampton, W.J., Dash, J., Watmough, G., Milton, E.J., 2013. Evaluating the capabilities of Sentinel-2 for quantitative estimation of biophysical variables in vegetation. ISPRS J. Photogramm. Remote Sens. 82, 83-92.

Ghiyamat, A., Shafri, H.Z.M., Amouzad Mahdiraji, G., Shariff, A.R.M., Mansor, S., 2013. Hyperspectral discrimination of tree species with different classifications using single- and multipleendmember. Int. J. Appl. Earth Obs. Geoinformation 23, 177191.

Hagolle, O., Huc, M., Dedieu, G., Sylvander, S., n.d. SPOT4 (Take 5) Times series over 45 sites to prepare Sentinel-2 applications and methods.

Hansen, M.C., Potapov P.V., Moore R. et al. 2013. Highresolution global maps of 21st-Century forest Cover change. Science, 342 (6160), 850-853.

Hojas Gascón, L., Eva, H., European Commission, Joint Research Centre, Institute for Environment and Sustainability, 2014. Field guide for forest mapping with high resolution satellite data. Publications Office, Luxembourg.
Hojas Gascón L., Eva H., Cerutti Paolo 2015. Policy report: Lessons learnt in monitoring deforestation and forest degradation in the context of REDD+. For publication.

INPE 2014. Projeto Prodes - Monitoramento Da Floresta Amazônica Brasileira Por Satélite, INPE, São José dos Campos, Brazil. http://www.obt.inpe.br/prodes/index.php

IPCC 2003. Definitions and methodological options to inventory emissions from direct human-induced degradation forest and vegetation of other vegetation types. Ninth session of the Conference of the Parties (COP 9). http://unfccc.int/meetings/milan_dec_2003/session/6271/php/vi ew/reports.php

OECD 2007. Financing mechanisms to reduce emissions from deforestation: issues in design and implementation. Retrieved on $20^{\text {th }} \quad$ February 2014 from: http://www.oecd.org/env/cc/39725582.pdf

Padma, S., Sanjeevi, S., 2014. Jeffries Matusita based mixedmeasure for improved spectral matching in hyperspectral image analysis. Int. J. Appl. Earth Obs. Geoinformation 32, 138-151.

Rodriguez-Galiano, V.F., Ghimire, B., Rogan, J., Chica-Olmo, M., Rigol-Sanchez, J.P., 2012. An assessment of the effectiveness of a random forest classifier for land-cover classification. ISPRS J. Photogramm. Remote Sens. 67, 93104.

Swain, P.H., 1972. Pattern recognition: a basis for remote sensing data analysis.

UNFCCC 2011. Report of the Conference of the Parties on its sixteenth session, held in Cancun from 29 November to 10 December 2010. http://unfecc.int/resource/docs/2010/cop16/eng/07a01.pdf

UNFCCC 2009. Report of the Conference of the Parties on its fifteenth session, held in Copenhagen from 7 to 19 December 2009. http://unfccc.int/resource/docs/2009/cop15/eng/11a01.pdf

UNFCCC 2001. Report of the Conference of the Parties on its seventh session, held at Marrakesh from 29 october to 10 november 2001. http://unfccc.int/resource/docs/cop7/13a01.pdf

UN-REDD 2013. Roadmap for Development of a Reference Emission Level / Reference Level for the United Republic of Tanzania. Discussion draft - v1.

UN-REDD 2009. Tanzania final UN-REDD National Joint Programme. Retrieved on 7th January 2014 from: http://www.unredd.org/UNREDDProgramme/CountryActions/T anzania/tabid/1028/language/en-US/Default.aspx 
The International Archives of the Photogrammetry, Remote Sensing and Spatial Information Sciences, Volume XL-7/W3, 2015 36th International Symposium on Remote Sensing of Environment, 11-15 May 2015, Berlin, Germany

\section{APPENDIX}

Table 4. JM distance matrix between the different forest classes from the SPOT data (simulating Sentinel-2 A and B) classification.

\begin{tabular}{|c|c|c|c|c|c|c|c|c|c|c|c|c|c|c|c|c|c|c|c|c|c|}
\hline 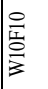 & है & $\ddot{\infty}$ & 索 & 잉 & $\Xi$ & ڤ్ & $\infty$ & 售 & 俤 & 尺్m & $\mid \stackrel{r}{f}$ & 苧 & 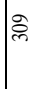 & 8 & m & f f & 은 & $\Xi$ & 18 & 18 & 0 \\
\hline 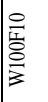 & $\mathbb{I}$ & ま & $\partial$ & $\tilde{\sigma}$ & ‡ & $\underset{\circledast}{ \pm}$ & శ్ర & 哭 & $\approx$ & m & 字 & : & 写 & in & $\stackrel{m}{m}$ & 然 & 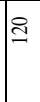 & $\cong$ & $\approx$ & 0 & 18 \\
\hline \begin{tabular}{|l} 
畄 \\
离
\end{tabular} & 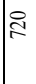 & $I$ & के & $\bar{\sigma}$ & 영 & \pm & $\stackrel{\circ}{\circ}$ & 票 & \% & $\stackrel{\mathrm{m}}{ }$ & $\bar{F}$ & 靑 & 票 & 6 & $\stackrel{\curvearrowright}{\approx}$ & $\stackrel{\sim}{\approx}$ & $\bowtie$ & $\grave{\varrho}$ & 0 & $\approx$ & 18 \\
\hline 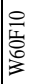 & 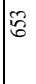 & 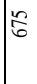 & $\stackrel{\mathrm{m}}{ }$ & $\infty$ & 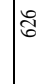 & $\widetilde{\varrho}$ & is & 莳 & $\stackrel{\text { }}{F}$ & $\frac{\mathrm{H}}{\mathrm{N}}$ & శ్లি & I & I & $\cong$ & $\Phi$ & $\stackrel{\circ}{\varrho}$ & I & 0 & 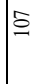 & 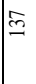 & $\Xi$ \\
\hline 詹 & $\mathscr{6}$ & Fे & ळे & $\infty$ & 㠻 & $\cong$ & 茫 & $\dddot{q}$ & 染 & $\approx$ & fy & 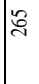 & $\cong$ & $\infty$ & 2 & $\partial$ & 0 & $\stackrel{+}{\mathrm{N}}$ & $\infty$ & 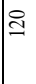 & in \\
\hline 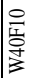 & 倠 & 㤩 & $\stackrel{\circ}{0}$ & 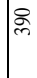 & 过 & 黑 & 壳 & 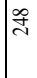 & $\vec{a}$ & F & $\tilde{\sim}$ & $\ddot{0}$ & F & ळి & $\underset{ \pm}{\infty}$ & 0 & 2 & $\cong$ & $\underset{\sim}{~}$ & ळ్లి & f \\
\hline 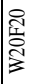 & శ్రి & if & के & 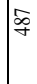 & 品 & 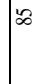 & 䆘 & ర్ల & fic & 过 & $\check{~}$ & 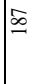 & I & 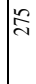 & 0 & $\stackrel{\infty}{9}$ & 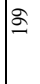 & $\infty$ & 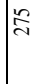 & 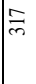 & ळ \\
\hline 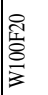 & $\approx$ & ほ & $\cong$ & 鸪 & $\S$ & $\cong$ & 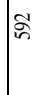 & 字 & in & ஓ्లి & $\overline{\mathcal{F}}$ & f & $\overrightarrow{\Im ন ~}$ & 0 & $\stackrel{\curvearrowright}{\curvearrowright}$ & 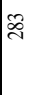 & $\infty$ & 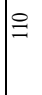 & 0 & in & 3 \\
\hline $\begin{array}{l}\text { 产 } \\
\text { 岕 }\end{array}$ & 然 & : & $\cong$ & $\bar{F}$ & 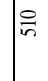 & $\cong$ & $\stackrel{n}{m}$ & 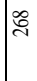 & సે & $\alpha$ & $\approx$ & 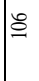 & 0 & $\overrightarrow{\Im ন ~}$ & \pm & f & 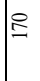 & I & 孚 & 总 & ১্ল \\
\hline 番 & क्ष & is & $\stackrel{\infty}{=}$ & $\vec{m}$ & 表 & \pm & $\cong$ & 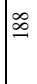 & 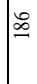 & F & $\infty$ & 0 & $\cong$ & f & $\Phi$ & $\mathscr{\theta}$ & 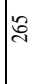 & ปี & 焦 & $\mid$ & 学 \\
\hline 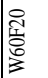 & $\frac{}{7}$ & $\tilde{q}$ & 8 & 胥 & চ్ర & $\stackrel{\infty}{\beth}$ & $\approx$ & $\cong$ & $\overline{\underline{ }}$ & $\Xi$ & 10 & $\infty$ & $\nsubseteq$ & $\overrightarrow{\mathcal{F}}$ & 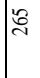 & $\stackrel{\approx}{\Omega}$ & fy & శ్లి & F & $\dddot{q}$ & 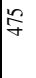 \\
\hline 喥 & $\overline{\text { in }}$ & î & $\stackrel{\infty}{\stackrel{2}{n}}$ & ) & ğ & $\because$ & $\stackrel{m}{m}$ & సి & สิ & lo & $\Xi$ & F & $\approx$ & శ్లి & I & $\mathscr{F}$ & 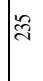 & $\stackrel{ \pm}{\sim}$ & $\stackrel{m}{m}$ & f & 尺) \\
\hline 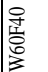 & fo & 所 & $\cong$ & in & 胥 & ह & $\Xi$ & 佔 & 10 & নિ & $\bar{\Xi}$ & 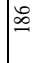 & సે & $\vec{m}$ & 临 & $\vec{ন}$ & 寁 & $\stackrel{2}{\rightleftharpoons}$ & \% & ๙્નિ & مై \\
\hline \begin{tabular}{l} 
㸒 \\
高 \\
\multirow{3}{*}{}
\end{tabular} & శ్లి & ల్లి & $\bar{a}$ & $\sqrt{n}$ & $\stackrel{\lambda}{\nexists ~}$ & $\stackrel{\mathrm{m}}{\mathrm{m}}$ & $\cong$ & 0 & in & స్తి & $\stackrel{\leftrightarrow}{\varrho}$ & $\stackrel{\circledast}{\stackrel{\circ}{2}}$ & $\infty$ & 字 & $\vec{~}$ & 晃 & ‡ & 莳 & 䒯 & 瓷 & if \\
\hline 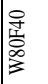 & $\overrightarrow{\widetilde{\lambda}}$ & F্ & స్ & ले & $\stackrel{0}{0}$ & F & 0 & $\cong$ & $\Xi$ & m & $\approx$ & ఊి & 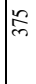 & 嫁 & i⿱宀子 & 岕 & 芯 & is & ஜ & 8 & 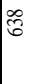 \\
\hline 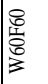 & $\approx$ & 菒 & $\dddot{\text { }}$ & 营 & $\tilde{\delta}$ & 10 & 字 & E్ల & E & $\stackrel{2}{2}$ & 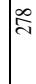 & 吉 & $\cong$ & $\cong$ & $\infty$ & \pm & $\cong$ & $\Xi$ & It & 芯 & 瓷 \\
\hline 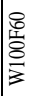 & $\approx$ & 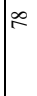 & స్లి & $\cong$ & 0 & శ్రి & $\ddot{\infty}$ & 고 & $\approx$ & 辛 & స్ల & 表 & in & §ิ & 禺 & \% & 要 & శ్ర & g. & 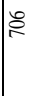 & $\mp$ \\
\hline $\begin{array}{l}\text { 啻 } \\
\text { 总 }\end{array}$ & 究 & $\stackrel{\sim}{\sim}$ & $\stackrel{\text { 年 }}{\mathrm{s}}$ & 0 & $\cong$ & 索 & ले & $\sqrt{n}$ & in & 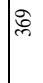 & 於 & $\bar{m}$ & $\bar{F}$ & त्ర & 衣 & 启 & 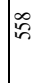 & $\stackrel{\infty}{\infty}$ & $\bar{\sigma}$ & $\tilde{\sigma ్ ర ె ౖ ~}$ & bे \\
\hline 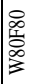 & 茔 & $\stackrel{\text { f }}{f}$ & 0 & $\underset{d}{\beth}$ & బ్లి & $\dddot{\curvearrowright}$ & సิ & 5 & $\cong$ & $\stackrel{\infty}{\stackrel{2}{2}}$ & 8 & $\cong$ & $\stackrel{\varrho}{\simeq}$ & $\frac{7}{7}$ & 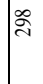 & 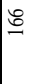 & ळ్ & $=$ & 字 & $\partial$ & 李 \\
\hline 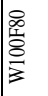 & চ & 0 & $\stackrel{\curvearrowleft}{\digamma}$ & $\stackrel{\sim}{\sim}$ & $\infty$ & 莺 & $\overparen{d}$ & हె & हn & iి & $\dddot{q}$ & 䛔 & مיم: & ¡ & if & 莒 & $\bar{\sigma}$ & 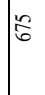 & 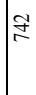 & き & $\underset{\propto}{\infty}$ \\
\hline \multirow[t]{2}{*}{8} & 0 & চ & 茔 & 茕 & $\approx$ & $\tilde{\Xi}$ & $\bar{\curvearrowright}$ & ন্লি & f & 枀 & $\stackrel{\circ}{7}$ & 产 & 夆 & $\tilde{\imath}$ & ప్రి & 票 & 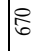 & $\tilde{\hat{\sigma}}$ & సి & I & îे \\
\hline & $\begin{array}{l}\frac{8}{2} \\
\text { 产 } \\
\frac{8}{2}\end{array}$ & 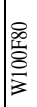 & 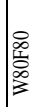 & 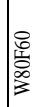 & 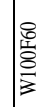 & | & 楌 & 㝵 & 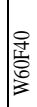 & 将 & 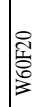 & 倠 & 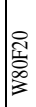 & 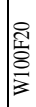 & 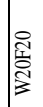 & 옿 & 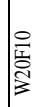 & 浐 & 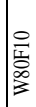 & $\begin{array}{l}\text { 을 } \\
\text { 妾 } \\
\frac{3}{3}\end{array}$ & 遍 \\
\hline
\end{tabular}

